\title{
Informe
}

\section{Expedición Manizales 150 años}

Jorge Ronderos V.*

\begin{abstract}
$\longrightarrow$
El proyecto es de carácter cultural, interdisciplinario e interinstitucional, dinámico, en ántora proceso permanente de estructuración y formulación teórico práctico, orientado hacia la investigación, educación, recreación y promoción de la identidad y cultura regional y local de Manizales, articulado al componente ambiental, como contexto fundamental para el desarrollo y consolidación de cualquier alternativa social hacia el futuro. En los recientes avances de la biología y la ecología, existen grandes posibilidades para explorar y contextualizar enfoques de trabajo «transdisciplinario» con las ciencias sociales básicas tradicionales, para abordar el estudio y la práctica social en torno a la cultura.
\end{abstract}

Hoy, en nuestro país, por las crisis y las formas en que se expresan, es una necesidad histórica y urgente gestar procesos sociales, orientados hacia el autoreconocimiento y autodescubrimiento de nuestra identidad cultural, para buscar y construir alternativas de solidaridad y cohesión social.

El modernismo ha impuesto como paradigma de identidad personal, marcas y mercancías determinadas, que refuerzan imaginarios y status sociales que satisfacen, en mayor o menor medida gustos personales sin importar sus implicaciones y costos, así estén por fuera de sus posibilidades
Manizales, el 12 de Octubre de 1.999, cumple 150 años de haber sido erigido como Distrito Parroquial. Uno de los múltiples proyectos para celebrarlo es el de la Expedición Manizales 150 años. En esta entrega para la Revista ánfora, presentamos para ilustración de los lectores los objetivos de la Expedición y algunos elementos teóricos que la fundamentan. socioeconómicas. En esta situación se desvalorizan las historias locales, se pierden los rasgos y características de la identidad cultural nativa, sin tener la posibilidad de reconstruirla a partir de procesos propios y de cohesión social. Se destruye lo que se tiene simplemente porque "lo nuevo", lo foráneo o lo «extranjero» es lo mejor siempre y cuando suponen formas de modernización y

* Sociólogo de la Universidad Nacional. Profesor Asociado de la Universidad de Caldas, adscrito a la Facultad de Desarrollo Familiar. Director del Proyecto Expedición Manizales 150 Años. 
modernidad. De esta forma el individuo coloca las metas más allá de su espacio e incluso del tiempo cultural, generando así procesos de ruptura enajenantes con la familia, los amigos, la ciudad, la región, las creencias propias y en donde el sentido del encuentro con ellos, queda en el plano de la ansiedad y la frustración.

Nuestro proceso de imbricación cultural manizaleño, es el resultado de formas de «mestizaje cultural» como las define Otto Morales Benítez. Que hay que aceptarlo como conflictivo y contradictorio, en tanto es dinámico, está en movimiento. De lo que se trata es de encontrar caminos de apropiación colectiva, populares, de nuestra historia y cultura, que impliquen generación de sentimiento y proyección de identidad local, de sentido de vida a través de formas y expresiones alternativas y activas de solidaridad e igualdad.

Nuestra identidad «manizaleña», es tambien muy jóven, lo cual nos permite la posibilidad de estructurar pautas de comprensión y rasgos para construir senderos de vida alternativos. Como aproximación podríamos señalar que «lo manizaleño» o «lo manizalita» tiene su génesis cultural en la formación antioqueña, mediado y transformado por la Colonización Antioqueña "manizaleña», el carácter mercantil en su estructuracón urbano regional, mediado por un dinámico mercado local e interregional, ligado a procesos internacionales (oro, tabaco y especialmente el café). Así, Manizales se ha conformado progresivamente como una realidad cultural urbano comercial e industrial, con diversas formas y grados de hegemonías y dependencias, caracterizados por los momentos hiatóricos queha tenidoen su desarrollo sesquicentenario.

La colonización antioqueña, devastó inmisericordemente la flora y la fauna y propició el deterioro de los suelos (probablemente en un grado no menor al impacto de la tecnología del café «caturra» y la «Variedad Colombia» después de la decada de 1970) lo cual fue lamentablemente un proceso necesario en su momento para la conformación de esta sociedad regional. No había opción!

Hoy, en la construcción de alternativas culturales, debemos entenderlo para generar elementos que ayuden a estructurar nuestra cultura regional y nacional, en la cual la dimensión de la protección y la conservación ambiental, de nuestros recursos naturales renovables y no renovables, sea un fundamento de viday sentimiento. Esto nos puede ayudar a desarrollar acciones en torno a una sólida convivencia social que debilite y aisle progresivamente, los factores de riesgo que genera el consumismo dominante.

¿Es un sueño? ¿una utopía? En nuestra consideración lo planteamos como una alternativa histórica y socialmente viable siempre y cuando ella se fundamente en la reconstrucción de un ser regional. Esto por supuesto es una tarea colectiva que implica, en cierta forma, un sentido de «misión» o proyecto político.

Un espíritu de cooperación en torno a la ciudad como prototipo étnico, se expresó en múltiples formas y acciones,configurándose una identidad quealimentó sentimientos de orgulloy pertenencia local, la cual se estructuró en el nivel profundo del colectivo, que progresivamente, en especial después del Centenario de la ciudad, ha tendido a debilitarse y extinguirse.

Precisemos algunos rasgos generales sobre nuestra identidad. El deseo de conocimiento y aventura, el espíritu de conquista del entorno; un sentimiento de lucro combinado en lo pasional y racional; la valentía y el arrojo que combinan y se relacionan contradictoriamente con la vida y la muerte, en la aparente solución de conflictos expresados en las diversas formas de violencias; el sentimiento de cariño y aprecio por la tierra y sus ancestros, por sus obras y realizaciones; la inclinación por el arte y el buen gusto en el vestir y vivir,en la comida abundante como sinónimo de fuerza y bienestar; la solidaridad y el compromiso con lo propio,expresado también con inteligencia 
y melancolía en la música, la literatura e incluso la política; la configuración de una ética católica y ajustada a las mismas contradicciones del afecto, el honor, el amor,el sexo, la pasión y el dolor; la familia como centro de vida y máxima valoración jerárquica entre otros.

¿Qué rasgos y características de tales componentes sobreviven, cómo se han modificado, qué podemos conservar, qué debemos transformar y porqué?. Es esta la tarea cultural que es necesario afrontar. Las Universidades de Manizales, asociaciones profesionales y cívicas, las familias, grupos, empresas, la Iglesia Católica y religiones cristianas y las demás expresiones de la sociedad civil aunados a la Alcaldía y Concejo Municipal, tiene una misión en este sentido qué cumplir.

En este contexto es necesario no olvidar el aporte y la inserción de las culturas extranjeras, principalmente europeas, en la conformación de esta entidad regional, sin omitir presencias de origen palestino y del oriente medio, como la más reciente de origen norteamericano, vinculada especialmente al café.Ellas dieron su aporte, especialmente en lo relacionado con la ciencia, la técnica, el comercio y el dinero.No hay que olvidar que la primera expedición al Ruiz fue proyectada por los alemanes Dangerhat quienes vinieron cargados de aparatos de medición, cuando aun el poblado no se había fundado. Lo extranjero se construyó como alternativa de progreso y apertura. De allísu buena aceptación y reconocimiento, el status que ha logrado en el medio.

El espíritu de lo práctico y lo útil, el sentimiento de lucro, también de confraternidad, tan familiar anuestra rasgos de identidad, podrían relacionarse con este aporte que se asume colectivamente y que bien se "amestiza» en el arriero; igualmente se expresa en el intelectual por su interés en el conocimiento y en el artista en la pasión por las artes. Todo esto, aunadoaaires de podery alcurnia, se imbrican en las oligarquías que se conforman para dominar y explotar la región y se traduce como un espíritu regional, que se transforma y reproduce a través de conflictos de apropiaciones y desarraigos. La diversidad y sus manifiestas diferencias subculturales o contraculturales y sociales, constituyen el sustrato de nuestra cultura local y regional.

La Expedición es un camino de autoreconocimiento cultural a través de las ciencias sociales: la historia, la sociología, la antropología, la politología, la economía, la psicología. También de las denominadas naturales: la biología, la ecología, la geografía, la geología, la química.

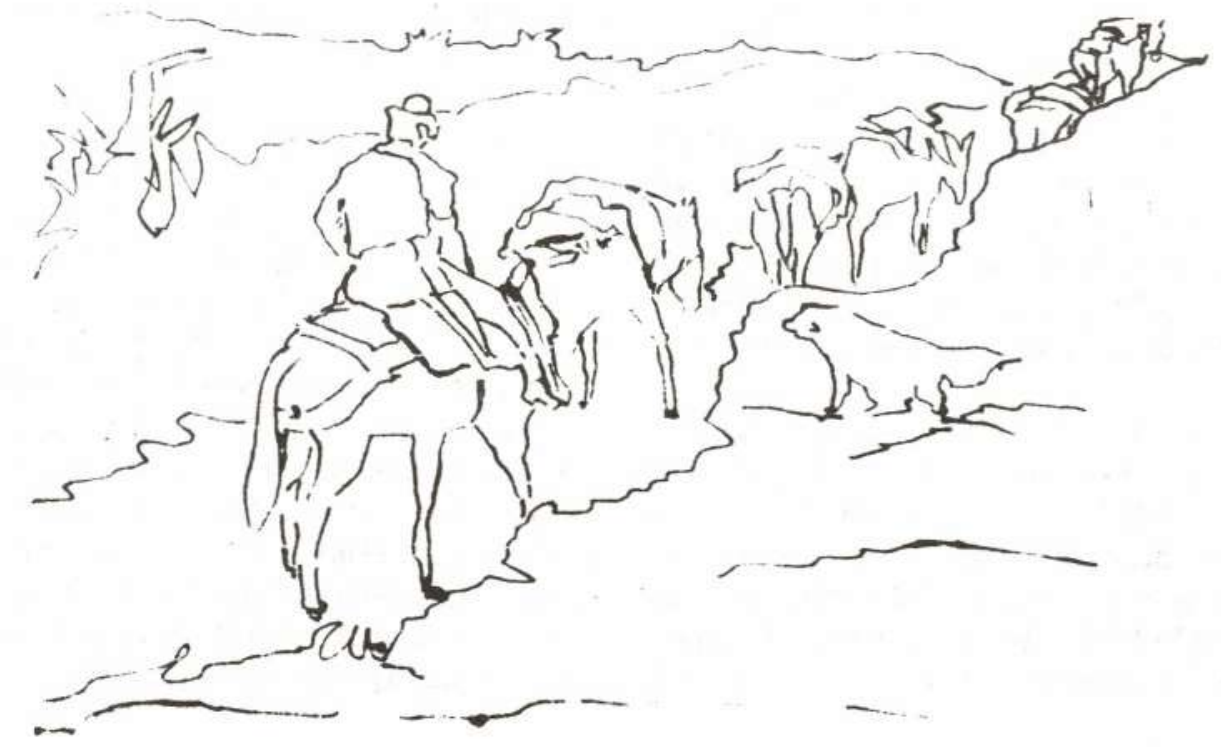

54 ánfora 3- 1994 
También de las clasificadas como naturales de la física, la astronomía y demás disciplinas básicas, ayudados por las tecnonologías y las profesiones. De esta forma la Expedición se apoya en las ciencias y disciplinas, para estructurar una estrategia mixta, pero participante para el logro de sus objetivos. Por lo anterior, una estrategia esencial debe ser el vínculo con las universidades y centros educativos de la región, con énfasis en la ciudad de Manizales, en tanto estos son los difusores y creadores de conocimiento.

Lo anterior debe concretarse en un proceso pedagógico activo y participativo, organizativo, profundamente comunicativo, que pretende nuclear a sectores sociales diversos de lả región, muy especialmente a quienes tengan interés por convertirse en agentes protagónicos de su sociedad y estén dispuestos a luchar positivamente por alternativas viables, orientados a construir un futuro con identidad regional y posibilidad de existencia humanista y solidaria, justa y digna, que permita superar los desequilibrios y las inequidades. Una cátedra libre, a través de diversas técnicas pedagógicas que integren investigación, docencia y recreación es la propuesta de trabajo que tenemos para integrar este proceso. La Cátedra Libre Manizales 150 Años, debe llegar a las diversas fuerzas y expresiones de la sociedad civil.

Universidades y Alcaldía tienen en esta actividad, su mayor responsabilidad.

El concepto de expedición que adoptamos, es alusivo históricamente a la «Expedición Botánica» de Mutis, por sus aportes a la ciencia, especialmente la botánica, pero de manera especial por el significado cultural de valorar y reconocer nuestro entorno e identidad, abriendo el horizonte intelectual y la inteligencia.

Tambien hace referencia a las exploraciones de la colonización antioqueña desde la famosa «Expedición de los Veinte» y todas aquellas anónimas que los pobladores y sus familia realizaron para descubrir el territorio.
Semánticamente, recoge el concepto de libertad plena en el camino del conocimiento, en la exigencia de superar convencionalismos para la búsqueda de verdades. Esto implica una libertad de disciplinas y métodos para acometer esta tarea.

El gran obstáculo por vencer, es modificar en jerarquía social el valor humanista de la vida frenteal cotidiano práctico y utilitarista del mundo material e inmediatista. Es una tarea universal, que es necesario y urgente acometer en el escenario de la cultura local y regional. En últimas es la tarea que desde hace milenios comenzó. Privilegiar ante todo la educación y el conocimiento con sentido humanista para lograr el descubrimientoconstrucción de una identidad y sentido de vida es uno de los senderos. Por el contrario, seguir privilegiando la oscuridad y la destrucción en el consumismo inmediatista, en laaparienciamaterial del mundo cotidiano, en la estética de lo aparente, en el poder del lujo y el confort elitista, es escoger el sendero de la enajenación de la vida. La Expedición es una propuesta para avanzar en el primero de los indicados.

Finalmente. Los senderos expedicionarios están abiertos a todos quienes quieran comprometerse en la aventura maravillosa del autoreconocimiento y autodescubrimiento cultural. Quiénes somos? Cual es nuestro ser manizalita? Porque somos asî? En qué creemos y porqué? De donde vinieron y quienes son nuestros ancestros? Cuál es el sentido histórico de nuestra existencia individual y colectiva? A dónde dirigirnos? Cómo hacerlo? Qué vamos a hacer en estos próximos años para conmemorar los 150 Años de existencia de esta ciudad en la que hemos nacido, vivido o quizá simplemente permanezcamos transitoriamente como estudiantes, profesores, empleados o trabajadores?

Nota: Cualquier información adicional solicitarla al Apartado 275 o teléfonos 860327/861250, Ext. 409/ 410, Universidad de Caldas, Manizales. 


\section{Objetivos de expedición Manizales 150 años}

1 Contribuir protagónicamente a través de un proceso de pedagogía activa, al autodescubrimiento y autoreconocimiento cultural de Manizales como región, en sus 150 años de existencia.

2 Fortalecer lazos de identidad y solidaridad cultural y regional de Manizales.

3 Contribuir a sensibilizar e interesar a los manizaleños y sus familias, a los municipios caldenses y tolimenses vecinos, a las entidades privadas y gubernamentales, por su historia, cultura y región.

4 Propender por dinamizar procesos educativos de protección y recuperación ambiental que garanticen neutralizar en el mediano plazo, los fenómenos de deterioro y destrucción de los recursos naturales de su región.

5 Apoyar acciones que contribuyan a elevar la autoestima colectiva por la ciudad y la región .

6 Propender por la construcción de valores alternativos que interpreten nuestra idiosincracia, símbolos y hechos de significado cultural.

7 Contribuir a la divulgación y apropiación colectiva de conocimientos y hechos que la historiografía, las ciencias y las profesiones han hallado en nuestro medio y hacen parte del patrimonio cultural manizaleño.

8 Reforzar el interés por la ciencia y el arte, como campos del saber y el ser.

9 Apoyar las actividad investigativa, creativa y recreativa que las diversas entidades gubernamentales y no gubernamentales vienen adelantando para contribuir al desarrollo del conocimiento científico de nuestra realidad cultural y las propuestas alternativas que sus resultados sugieran.

10 Propiciar formas de integración entre los municipios involucrados en la región.

11 Propiciar y gestionar acciones conducentes a la divulgación de los resultados de los proyectos y subprogramas, que contribuyan a la conmemoración del Sesquicentenario de Manizales en 1999

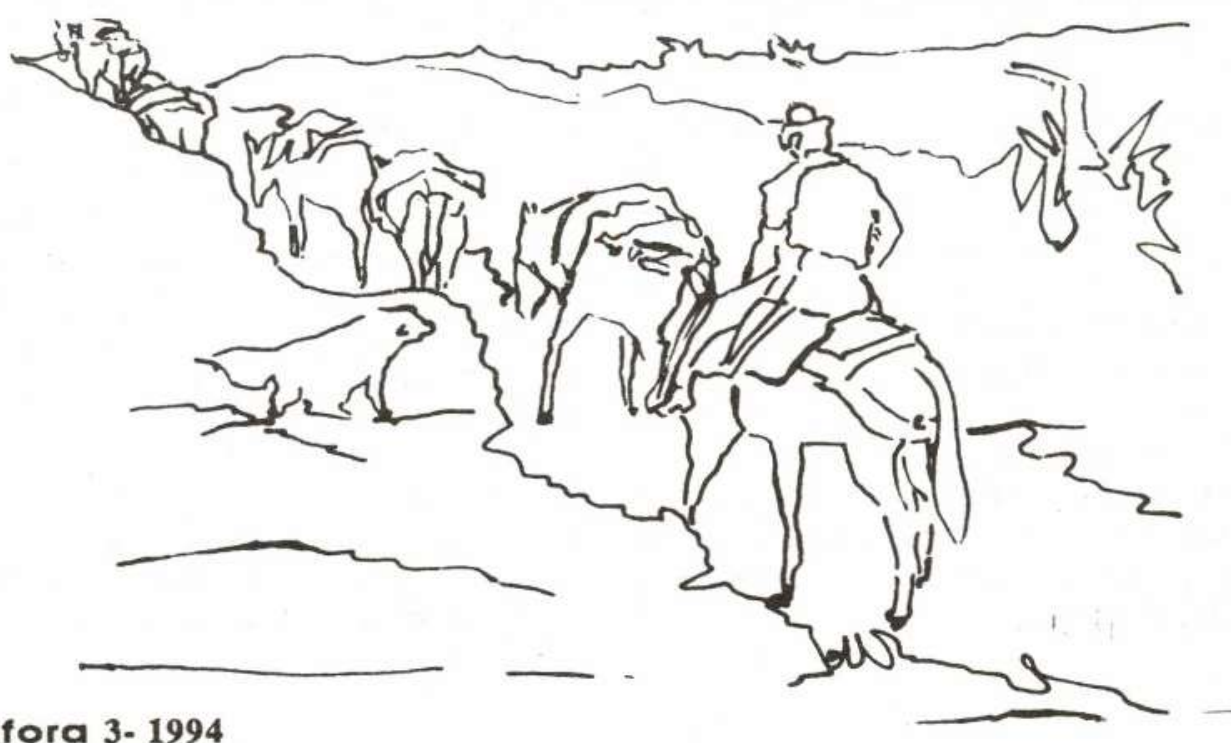

